\title{
The Mammary Gland Vasculature Revisited
}

\author{
Anne-Catherine Andres • Valentin Djonov
}

Received: 9 July 2010 / Accepted: 4 August 2010 /Published online: 14 August 2010

(C) Springer Science+Business Media, LLC 2010

\begin{abstract}
Concomitant with the extensive growth and differentiation of the mammary epithelium during pregnancy and lactation, and epithelial involution after weaning, the vasculature of the mammary gland undergoes repeated cycles of expansion and regression. Vascular expansion is effected by sprouting angiogenesis, intussusception and conceivably also vasculogenesis. The capacity of the epithelial cells to stimulate vascular growth and differentiation is dependent on the constellation of systemic and local hormones and growth factors as well as the changing demands for oxygenation and nutrient supply. This results in the release of angiogenic factors which stimulate endothelial cell growth and regulate vascular architecture. In contrast to the angiogenic phase of the mammary gland cycle, little is known about the control of vascular regression although this would possibly offer new insights into therapeutic possibilities against breast cancer. In this review we summarize knowledge regarding the mechanisms regulating the vasculature of the mammary gland and delineate the importance of the vasculature in the attainment of organ
\end{abstract}

The financial support by the Swiss National Science Foundation (3100A_127168 to ACA; 3100A_166243 to VD), the Swiss Cancer League (KLS-02105-08-2007 to ACA) and the Schweizerische Stiftung für Klinisch-Experimentelle Tumorforschung (ACA), is gratefully acknowledged.

A.-C. Andres $(\square)$

Department of Clinical Research, University of Bern,

Tiefenaustrasse 120c,

CH 3004 Bern, Switzerland

e-mail: anne-catherine.andres@dkf.unibe.ch

V. Djonov

Institute of Anatomy, University of Bern,

Baltzerstasse 2,

CH-3012 Bern, Switzerland function. In addition, we discuss the angiogenic mechanisms observed during mammary carcinogenesis and their consequences for breast cancer therapy.

Keywords Breast carcinogenesis - Eph-ephrin - Estrogen . Intussusceptive angiogenesis · Prolactin - Vasculogenesis . VEGF
Abbreviations
VEGF vascular endothelial growth factor
MMP matrix metalloprotease
hif hypoxia-inducible factor
HEXIM hexamethylene bisacetamid-inducible protein
CAM cell adhesion molecule
MMTV mouse mammary tumor virus
SDF stroma-derived factor
CCL chemokine (C-C motif) ligand

The mammary gland cycle is unique among all organs of the body because its development mainly occurs postnatally and its organ structure changes repeatedly and drastically according to the hormonal environment and functional demands. In particular, the dramatic expansion of the parenchyma at the expense of the stromal/adipose tissue during pregnancy and the high secretory and metabolic activity of the epithelium during lactation impose a drastic change in the supply of oxygen, nutrients and fluid. Therefore, by necessity, not only the mammary parenchyma but also the mammary vasculature has to adapt repeatedly to the functional state of the organ. A similar situation can be observed in the ovary when the post-ovulatory follicle is converted to the glandular corpus luteum responsible for high progesterone synthesis and needs extensive vascularization. The 
important difference, however, lies in the fact that the corpus luteum degenerates when its function is no longer needed, whereas the mammary gland reverts to a quiescent state in preparation for a subsequent cycle of pregnancy and lactation. Thus, the mammary gland cycle gives a unique opportunity to study not only vascular expansion but also the controlled vascular regression as occurs during postlactational involution.

\section{Vascular Network Formation}

The development of blood vessels is critical for the maintenance of every functional organ system. Vascular development is mainly executed during embryogenesis, while post-natally it is limited to sites of injury and organs undergoing functional adaptation such as the hairy skin and the female reproductive organs. Moreover, vascular development plays a crucial role in many pathological conditions, most prominently during carcinogenesis. In the course of blood vessel formation two distinct processes are effective: vasculogenesis defining the de-novo formation of blood vessels from undifferentiated precursor cells, and angiogenesis that represents the formation of new vessels from pre-existing ones. Angiogenesis can then be further divided into sprouting and intussusceptive angiogenesis.

Sprouting angiogenesis was the first angiogenic mechanism discovered and can be divided into five distinct steps: (1) evasion of endothelial cells from their present location in the vessel wall, (2) endothelial proliferation, (3) guided migration and branching through the tissue, (4) threedimensional organization and tube formation and (5) recruitment of perivascular cells to attain their venous or arterial identity [1]. The main characteristics of sprouting angiogenesis, endothelial proliferation and the acquisition of an invasive phenotype are controlled by a multitude of angiogenic growth factors and matrix proteases, which are released in response to metabolic stimuli such as hypoxia or hypoglycaemia and to mechanical signals such as blood pressure and inflammation. In particular, vascular endothelial growth factor (VEGF) and Matrix Metalloprotease (MMP)-9 seem to play a dominant role in the initiation of sprouting angiogenesis. Interestingly, not all exposed endothelial cells are able to react to these stimuli. Only a few cells, designated as tip cells, are selected for outgrowth which ensures the maintenance of the pre-existing vessel integrity [2] (Fig. 1).

In contrast to sprouting, intussusceptive angiogenesis is a non-proliferative and non-invasive mechanism for the enlargement of the capillary plexus. During intussusception three major phases can be observed: intussusceptive growth, intussusceptive arborisation and intussusceptive remodelling (Fig. 1) [3]. Intussusceptive growth involves the initiation of transluminal pillar formation originating from the endothelial cell walls and their subsequent expansion resulting in the splitting of the existing vessel into two, thereby enhancing the vascular surface. Arborisation circumscribes the process of serial pillar formation which remodels the disorganized capillary network into a functional tree-like structure. Finally, the optimal adaptation
Figure 1 Diagram illustrating the mechanisms of blood vessel formation. Vasculogenesis and sprouting generate a primitive capillary plexus in an avascular tissue. As soon as the newly formed vessels are perfused, intussusception is triggered and is responsible for rapid capillary growth and expansion. Feeding vessels are subsequently segregated from the capillary plexus by intussusceptive arborization and finally the intussusceptive branching remodeling and vascular pruning optimize branching geometry and form the final vascular pattern (adapted from [77])
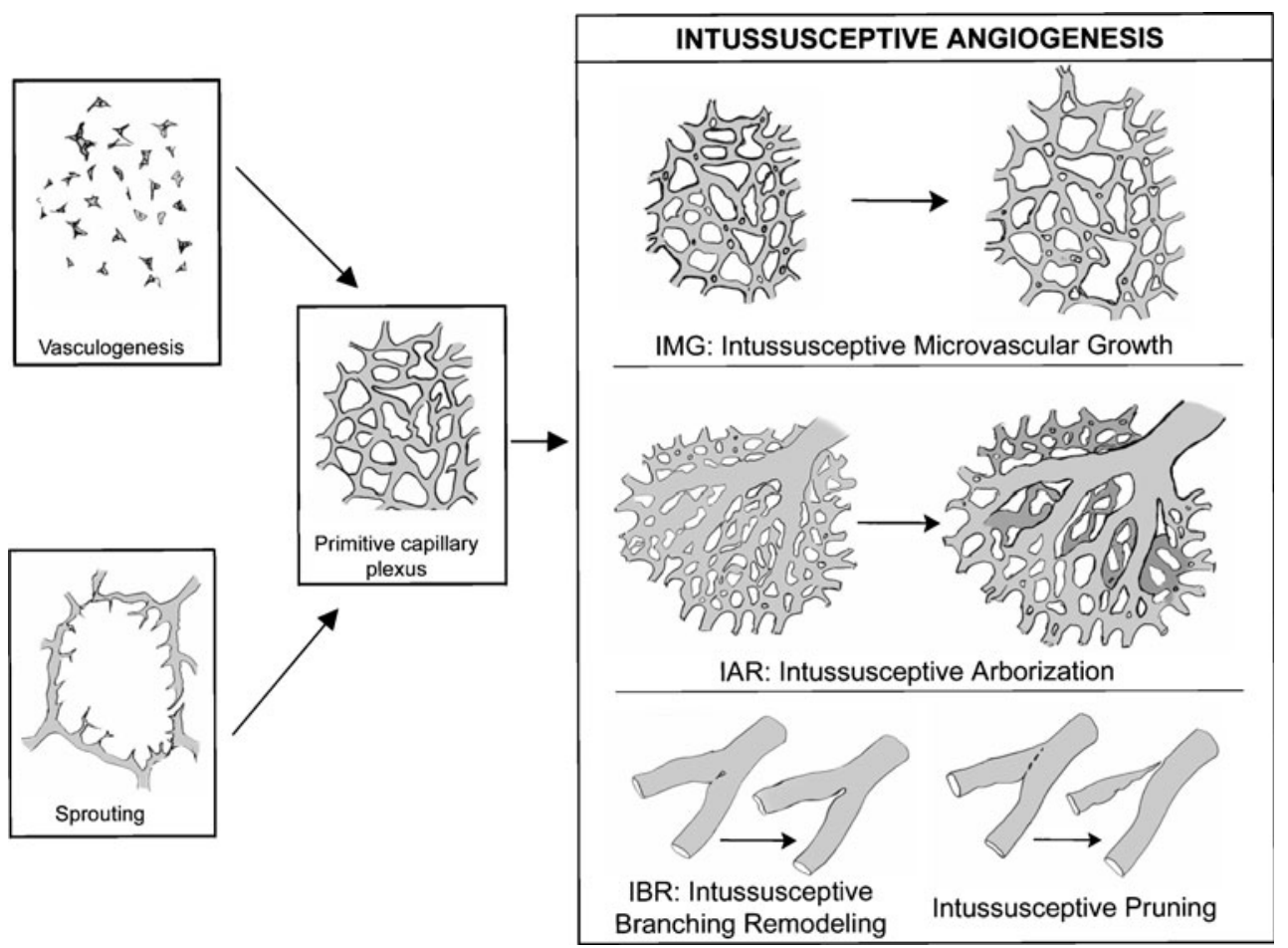
of the vascular geometry to the local needs is achieved during remodelling and involves the modification of branching angles and often the re-dimension of the capillary network by vascular pruning. Evidence gained from various vasularization model systems suggests that angiogenesis is mostly initiated by sprouting. Intussusceptive growth follows during the maturation phase and enables the fine-tuning and final spatial organization of the newly formed vascular network [4]. In contrast to sprouting angiogenesis, only limited information regarding the control of intussusception is available. Shear stress on the vessel walls has been suggested as one inducer of intussusceptive growth. Interestingly, this only holds true for laminar shear stress (in parallel to the vessel wall) while oscillating shear stress is involved in the induction of sprouting angiogenesis. Molecularly, VEGF and angiopoietin-1 are likely to synergistically regulate intussusceptive vascular expansion [4].

Vasculogenesis, the de novo formation of blood capillaries, has long been thought to be restricted to embryonic development. Only recently has it become evident that this process also contributes to vascular expansion post-natally. In the adult, haematopoietic stem cells, myeloid cells, side population cells of the bone marrow as well as tissue-resident pluripotent stem cells can be induced to differentiate into endothelial progenitor cells. These endothelial progenitors evade the stem cell niche and migrate to their place of destination where they proliferate and differentiate into blood capillaries (Fig. 1) [5]. The regulation of adult vasculogenesis is just starting to be investigated. Again, VEGF has been identified as key factor in the recruitment of endothelial progenitor cells from the bone marrow [6]. In addition, induction of MMP-9 and cathepsin-G expression results in the detachment of stem cells from their niche and in the cleavage of matrix-bound growth factors required for their differentiation to the endothelial lineage [7]. Interestingly, it has recently been shown that estrogen is able to mobilize inactive endothelial precursor cells and initiate neovascularization [8].

\section{The Microvasculature During Mammary Gland Development}

In the mouse, the vasculature of the mammary glands in mature virgin females is composed of a capillary plexus which runs in parallel or encircles the mammary parenchyma and ramifies throughout the adipose tissue. Mammary corrosion casts revealed an extensive expansion of the vasculature and an increase in the number of capillaries during pregnancy. The presence of numerous capillary sprouts during the first half of pregnancy indicates that vascular growth is initiated by sprouting angiogenesis. After day 14 of pregnancy, capillary sprouts disappear and the progressive occurrence of capillary pillars implies that during the last third of pregnancy and early lactation the vascular expansion switches from sprouting to intussusception. Furthermore, the honey-comb-like architecture of the capillaries enveloping a single alveolus, typical for the lactating gland, is initiated concomitantly with the switch in the angiogenic mode [9]. These observations suggest that mammary angiogenesis is mainly accomplished by sprouting and intussusception. It remains to be investigated whether de novo vasculogenesis from mesenchymal precursor cells may also contribute to the vascular expansion. It is well documented that the adipose tissue contains a stem cell fraction which is capable of differentiating into endothelial cells, being incorporated into capillary structures and contributing to vessel formation [10, 11]. Considering the large extent of adipose tissue in the quiescent adult mouse mammary gland, it is conceivable that this angiogenic mechanism might be effective at least at the beginning of pregnancy. Interestingly, not only does the extent of the vasculature increase during pregnancy, but also the individual endothelial cells increase their surface by the formation of numerous microvillous processes and marginal folds. Moreover, the endothelial cells exhibit an elevated number of mitochondria and pinocytotic vesicles as well as decreased cell-cell contacts thereby enabling the highly efficient transport of nutrients and fluids required during lactation $[12,13]$.

The secretory epithelium regresses by apoptotic cell death after lactation. The endothelium also regresses to the extent found in the quiescent mammary gland of adult female mice. Although the mechanisms of controlled vascular regression would have a major impact on angiogenesis-based therapeutic concepts, much remains unknown about the mechanism of vascular regression during mammary involution. Based on morphological criteria, apoptotic cell death is observed in endothelial cells although this may only partially account for the remodelling of the vasculature [14]. Interestingly, vascular obstruction and endothelial cell death peak around day 6 of involution, when epithelial cell death ceases and is replaced by tissue remodelling. This timing indicates that tissue reconstruction is initiated by the epithelium and the vasculature adapts to the altered environment [9].

In contrast to the rodent and bovine (reviewed in [15]) systems, little is known about vascularization of the human breast. For obvious reasons, developmental studies on the extent of the vasculature are hardly possible in the human breast and thus, only one detailed morphometric study exists in humans for breast tissue obtained from premenopausal women in the follicular phase of the estrous cycle [16]. In this study, the authors demonstrate that the 
mammary epithelium exhibits two different patterns of microvascularization. Ductal structures were found to be surrounded by a high number of small capillaries often without an identifiable lumen. In contrast, the acini of lobular structures were interspersed by fewer capillaries which, however, were significantly larger and sinusoidal in shape. This vascular geometry favours a slower blood flow and thereby a prolonged contact of the lobular epithelium with the circulating hormones.

\section{The Control of Mammary Vascularization}

\section{VEGF}

The formation of new blood vessels is tightly controlled by an array of stimulatory and inhibitory growth factors and hormones. VEGF (also termed VEGF-A) is the first member of pro-angiogenic cytokines identified and belongs to the heparin-binding growth factor family which includes VEGFB, VEGF-C, VEGF-D and placental-like growth factor. VEGF-A, subsequently termed VEGF, represents the predominant pro-angiogenic factor and exists in several splice variants $\left(\mathrm{VEGF}_{121}, \mathrm{VEGF}_{145}, \mathrm{VEGF}_{165}, \mathrm{VEGF}_{189}\right.$ and $\mathrm{VEGF}_{206}$ in humans), each exhibiting slightly different biological activities and sub-cellular localizations [17]. In addition, an alternative splicing distal of exon 8 results in the VEGF $_{\mathrm{XxX}} \mathrm{b}$ isoforms which exert anti-angiogenic effects [18]. Full-length VEGF plays a pivotal role in the induction of endothelial proliferation, migration and vascular permeability [17]. Thus, it has to be postulated that VEGF is also instrumental in the regulation of the mammary vasculature. Indeed, VEGF expression has been found to be differentially regulated at the transcriptional level in the mammary gland during pregnancy and lactation $[19,20]$. It has been shown that the VEGF protein is produced in the alveolar epithelial cells and that protein expression levels increase with the onset of pregnancy, peak at late gestation and gradually decrease during lactation and involution [21]. Two reports have addressed the role of parenchymal VEGF expression during mammary gland development and function. In the first report, transgenic mice exhibited a conditional knockout of VEGF in the mammary myoepithelium and epithelium. The VEGF knock-out led to a severe inhibition of lobulo-alveolar expansion during pregnancy and to impaired secretory activity of the epithelial cells during lactation. Interestingly, the microvascular density was not significantly reduced in the absence of VEGF. However, the vessels exhibited an almost complete loss of vascular permeability [22]. The other report investigated the role of VEGF in transgenic mice overexpressing $\mathrm{VEGF}_{165} \mathrm{~b}$ in the mammary epithelium during pregnancy and lactation. $V_{E G F}{ }_{165} \mathrm{~b}$ is a splice variant of VEGF which competes with VEGF for receptor binding and elicits a strong anti-angiogenic response. The inhibition of VEGF function in the transgenic animals led to a comparable phenotype of the mammary epithelium i.e. reduced alveolar development and lactational failure. In contrast to the VEGF knock-out, however, the vascular density was significantly reduced in the $\operatorname{VEGF}_{165} \mathrm{~b}$ transgenic mice [18]. This difference can be explained by the fact that in the first approach VEGF expression was abolished only in the parenchyma and the other cell types present in the mammary tissue may have ensured a sufficient level of VEGF expression to stimulate endothelial growth. In contrast, a dominant negative mutant was secreted by the mammary epithelium in the $\mathrm{VEGF}_{165} \mathrm{~b}$ transgenic mice leading to an inhibition of extracellularly present VEGF, and consequently, a reduction in vascular outgrowth.

Expression of VEGF and its induction of angiogenesis is mainly induced by the heterodimeric transcription factor hypoxia inducible factor-1 (hif-1). The hif- $1 \alpha$ subunit is the regulatory partner which under normoxid conditions is rapidly degraded. Under hypoxic conditions hif- $1 \alpha$ is stabilized and its transcription increased [23]. The role of hif- $1 \alpha$ in the regulation of mammary gland vascularization has been addressed in transgenic mice exhibiting a complete hif- $1 \alpha$ gene knock-out in the mammary epithelium [24]. Interestingly, abolishing the function of hif- $1 \alpha$ did not result in a decrease of vascular expansion at pregnancy and the capillary network at lactation was comparable to that of wild type mice. Although primary epithelial cells of the hif- $1 \alpha$ null females showed a drastic reduction of VEGF expression after exposure to hypoxia, the overall VEGF concentration was normal in the intact mammary glands. The loss of hif$1 \alpha$ function in the epithelium, however, led to a severe impairment of alveolar expansion and differentiation during pregnancy, to impaired lipid and milk protein secretion and thus to lactation failure. This phenotype closely resembles the effects observed after VEGF knockout in the mammary gland. Although not directly addressed in this report, it is likely that after the hif- $1 \alpha$ knock-out VEGF expression was induced by other mechanisms to stimulate vascular outgrowth (see below), but that the absence of hif- $1 \alpha$ led to an impairment of vascular structure and function.

These results demonstrate not only that VEGF and hif$1 \alpha$ have a crucial function in regulating the mammary vasculature but also that the proper development and functioning of the secretory epithelium is dependent on a well-developed, functional vasculature.

\section{Estrogen and Progesterone}

Estrogen and progesterone are of primary importance for mammary epithelial development during puberty, the 
estrous cycle and pregnancy. Whereas estrogen is mainly involved in ductal elongation and epithelial proliferation, progesterone is instrumental in branching morphogenesis and alveologenesis $[25,26]$. Considering their pivotal role in all aspects of mammary epithelial function, it is conceivable that these hormones may also be involved in the regulation of mammary vascularization. Indeed, it has been shown that estrogen is involved in angiogenic processes by two ways; by inducing the epithelium to impart angiogenic stimulation [27] and by directly acting on the endothelial cells [28].

The angiogenesis-related effects of estrogen on the mammary epithelium involve its direct or indirect regulation of pro- and anti-angiogenic factor production by epithelial cells [27]. A direct target of estrogen is the VEGF gene which contains a functional estrogen response element in its promoter [29], where transcription can directly be induced by estrogen in estrogen receptorpositive cell lines [30]. During normal mouse mammary gland development the highest VEGF levels have been found at late pregnancy (see above) while in humans VEGF levels increase two-fold during the luteal phase of the estrus cycle [31]. Since these developmental windows are characterized by high estrogen and progesterone levels, progesterone may synergize with estrogen to induce VEGF expression. Indeed, $\mathrm{Wu}$ and co-workers have shown that VEGF induction by estrogen is dependent on progesterone signalling via the progesterone receptor $B$, probably by up-regulating the expression of estrogen receptor- $\alpha$ [32]. In contrast to the direct activation of VEGF expression, estrogen also indirectly enhances VEGF production by inducing hif- $1 \alpha$ expression and recruiting Hif- $1 \alpha$ to the VEGF promoter [33, 34]. The transcription factor hexamethylene bisacetamid-inducible protein 1 (HEXIM1) has been shown to interact with estrogen receptor- $\alpha$ thereby decreasing its transcriptional activity. Transgenic mice expressing a conditional HEXIM1 knock-out mutant in the mammary gland show increased Hif- $1 \alpha$ and VEGF expression in the mammary gland and exhibit a five-fold increase in vascularization at lactation [35]. These results underscore the importance of estrogen in the priming of mammary epithelial cells for their induction of angiogenesis.

In addition to the mammary epithelium, endothelial cells also possess estrogen receptors and are responsive to estrogen [36]. Interestingly, not all endothelial cells in a given capillary express the estrogen receptor and it remains to be elucidated if the estrogen receptor-positive cells represent the tip cells responsible for sprouting. Estrogen itself does not induce the angiogenic response of endothelial cells, but potentiates virtually every step involved in angiogenesis such as endothelial proliferation, migration, differentiation and assembly of mature capil- laries [28]. Interestingly, estrogen is also involved in endothelial relaxation and induction of E-selectin, intercellular adhesion molecule (ICAM) and vascular adhesion molecule (VCAM) expression, components that are involved in the recruitment of immune cells to the site of requirement, normally injury [28]. This aspect is of particular interest in the context of mammary gland development, since there is accumulating evidence that peri-epithelial macrophages and leucocytes contribute substantially to the establishment of a functional organ structure [37].

\section{Prolactin}

In addition to steroid hormones, the proteohormone prolactin is equally important in the regulation of mammary epithelial proliferation, differentiation and milk protein gene expression [38]. In addition to its effects on the mammary epithelium, prolactin can also act as a stimulatory or inhibitory factor on growth, dilatation and remodelling of blood vessels. In its angiogenic function, prolactin can act as a circulating hormone or in an auto/paracrine fashion since, in addition to the pituitary gland; it is also expressed by endothelial cells [39]. The full-length protein is thought to promote angiogenesis, to alter the cytoskeleton and adhesive properties of endothelial cells and probably to support vasoconstriction. It has to be emphasized that the data concerning the above-mentioned effects are highly controversial suggesting that vascular networks at different locations may respond very differently to the hormonal stimulation [40]. In addition, it is not known if prolactin acts directly or indirectly on the endothelial cells, since endothelial cells from different locations differ in the presence and constellation of prolactin receptor isoforms on the cell surface [41-43]. So far, no data are available addressing the direct response of the mammary endothelium to prolactin. Given these controversial observations, an indirect effect of prolactin on mammary angiogenesis may seem more likely, since prolactin has been shown to enhance the expression of VEGF in a variety of cell types including mammary epithelial cells [44].

In contrast to its stimulatory effect, the inhibition of angiogenesis by prolactin is well documented. Proteolytic cleavage of prolactin results in prolactin fragments ranging from 14 to $18 \mathrm{kDa}$, also known as vasoinhibins [45]. Cathepsin D was the first enzyme identified that was able to generate vasoinhibins [46]. Thereafter, several members of the MMP family as well as bone morphogenic factor 1-like metalloproteases were shown to process prolactin to vasoinhibins [47, 48]. Vasoinhibins act directly on the endothelial cells and inhibit growth factor-dependent proliferation, migration as well as tube formation and induce endothelial apoptotic cell death [40]. In the context of the mammary 
gland, cathepsin D-induced generation of vasoinhibins may be of particular interest regarding the observed attenuation of vascular expansion during lactation and regression during involution. Cathepsin D is a member of the pepsin family of proteases localized in lysosomes and endosomes and is thought to be active at an acid pH [49]. It has been shown, however, that lactating mammary epithelial cells release cathepsin $\mathrm{D}$ which is able to generate vasoinhibins at neutral $\mathrm{pH}$ outside the cells [50]. Interestingly, processing and polarized secretion of cathepsin $\mathrm{D}$ seems to be controlled by prolactin [51]. Cathepsin D is moderately expressed in the rodent lactating mammary gland and strongly induced $8 \mathrm{~h}$ after forced weaning. Moreover, enzyme activity is substantially increased by nitration 2 days after weaning [52]. Thus, although cathepsin D has been primarily implicated in the mitochondrial caspasedependent pathway of cell death [53], it may also be crucial for vascular regression during involution through its ability to generate vasoinhibins.

\section{Eph-ephrins}

The large family of Eph receptors and their membranebound ligands play key roles in a vast variety of morphogenic processes and adult tissue homeostasis. Receptor-ligand interaction requires direct cell-cell contact and elicits forward signaling form the receptor and reverse signaling emanating from the ligand leading to bidirectional cell-cell communication. Members of the Ephephrin family, predominantly EphB4 and ephrin-B2, have been implicated not only in the development of the embryonal vasculature but also in neo-vascularization in the adult. Endothelial expression of EphB4 and ephrin-B2 mediate the critical communication between arterial and venous endothelia whereas non-endothelial expression has been implicated in endothelial cell guidance [54]. Moreover, EphB4 has a regulatory function in the switch from sprouting to circumferential (endothelial proliferation within the vessel wall) angiogenesis and in vascular permeability [55]. Recent evidence also suggests that ephrin-B2 is instrumental in the spatial activation of VEGF-receptor internalization, thereby regulating the endothelial tip cell filopodial extension [56, 57].

We have shown that EphB4 and ephrin-B2 are expressed in the mammary parenchyma in a developmentally- and hormonally-regulated manner [58]. In order to elucidate the role of these two molecules in mammary gland biology, we have generated transgenic mouse models overexpressing EphB4 [59], ephrin-B2 or a dominant negative mutant of ephrin-B2 capable of receptor stimulation but unable to elicit reverse signalling [60] in the mammary epithelium. Transgene expression led to distinct phenotypic consequences for the mammary epithelial architecture and function.
Most notably, overexpression of EphB4 and the dominant negative ephrin-B2 mutant led to an incomplete outgrowth of alveolar structures during pregnancy, to delayed differentiation and to impairment of secretion. In contrast, overexpression of the native ephrin-B2 gene resulted in precocious alveolar differentiation during pregnancy and increased secretory activity during lactation. Beside the epithelium, distinct effects of epithelial transgene expression on the mammary vasculature have been observed. The vasculature in the lactating mammary glands of transgenic females overexpressing the native ephrin-B2 gene exhibited the same organized honeycomb-like capillary structure observed in wild type females. In contrast to the wild type situation, however, the alveoli were not surrounded by a single capillary layer but were enveloped by a bi- or even multilayered capillary ring (Fig. 2a and b) [60]. As observed for the epithelium, overexpression of EphB4 and ephrin-B2 affected the vasculature in a highly comparable manner. Lactating mammary glands of females from both transgenic strains exhibited a highly irregular vasculature in which the location of the alveoli was often barely discernable. Moreover, a surplus of irregular capillaries and many blind-ending capillary stumps were observed [60, 61] (Fig. 2c and d). These results indicate that intact EphB4-ephrin-B2 signalling in the mammary epithelium is indispensable for the proper organization and functioning not only of the epithelium but also of the mammary vasculature. Moreover, as observed in the VEGF or hif- $1 \alpha$ deficient mice, this model also emphasizes the correlation between mammary epithelial functionality and adequate development of the vasculature.

\section{Angiogenesis and Mammary Tumor Progression}

Nowadays it is common knowledge that blood vessel formation is indispensable for cancer growth, invasion and metastasis formation. As hyperplastic or tumor nodules grow, they require their own vasculature in order to ensure sufficient supply of nutrients and oxygen. The hypoxic conditions in the tumor nodule or its adjacent stromal tissue activate Hif- $1 \alpha$ and thereby the secretion of angiogenic factors [62]. Interestingly, not only hypoxia but also solely the loss of cell polarity, a hallmark of the transformation of hyperplastic lesions to cancer, is sufficient to induce the expression of VEGF in mammary epithelial cells [63]. The angiogenic switch from avascular to vascularized tumors and the clinical importance of angiogenesis in breast cancer diagnosis and treatment have been summarized in three excellent recent review articles [64-66]. Thus, in this review article we would like to highlight just the aspect of angiogenic mechanisms in mammary carcinogenesis. 
Figure 2 Scanning electron micrographs of mercox corrosion casts of the vasculature in the lactating mammary glands of wild type females (a) and transgenic females overexpressing ephrin-B2 (b), EphB4 (c) or a dominant negative ephrin-B2 mutant (d) in the mammary epithelium. Arrows point to bilayered capillary rings and arrow heads indicate blind-ending capillaries. Bars represent $25 \mu$
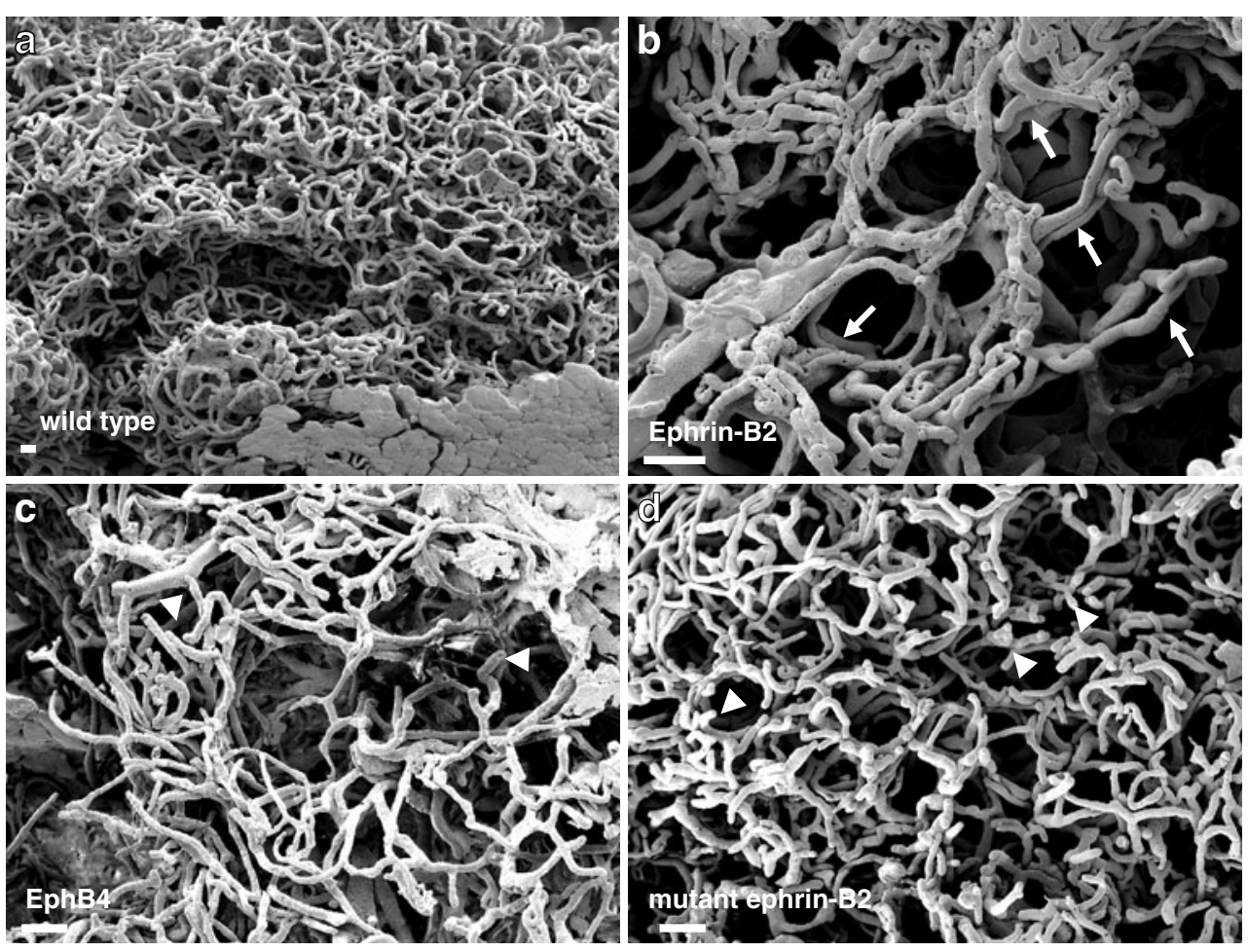

Although tumor angiogenesis has become a highly investigated target for therapeutic intervention, relatively little is known about the mode of angiogenesis in tumor development. Most likely, the angiogenic switch originating from the release of pro-angiogenic factors by the tumor cells induces sprouting angiogenesis in the first place. We have previously shown, however, that sprouting and intussuceptive angiogenesis occur side by side in established experimental mouse mammary tumors [9]. The mode of tumor angiogenesis is not a purely semantic issue but is of extreme importance regarding therapeutic approaches. Therapeutic regimens today involve mainly chemotherapy or irradiation. Blockers of angiogenesis, in combination or as unique agents, are also increasingly applied in the clinic, mostly involving agents blocking various components of the VEGF-induced signaling pathway. Thus, the current treatment concepts address fast dividing cells as the main constituents of the tumor mass and as sites of sprouting angiogenesis [65]. Although an initial response is achieved, tumor recurrence is a common phenomenon regardless of the chosen therapy. It has been shown that VEGF blocking agents induce selective apoptosis in immature capillaries as they are formed by sprouting angiogenesis. In contrast, mature blood vessels, covered with peri-endothelial cells such as smooth muscle cells or pericytes, are resistant to VEGF withdrawal [67]. We have demonstrated that after irradiation or VEGF receptor inhibition of MMTV-NeuT induced mouse mammary tumors this remaining mature vasculature is the origin of intussuceptive growth to restore the hemodynamic and structural integrity of the vasculature [68]. The transient switch of sprouting to intussuceptive angiogenesis probably takes place during treatment or immediately after its cessation. Tumor recurrence, observed about 1 week after treatment cessation, coincides with a switch to a second wave of sprouting angiogenesis. Thus, intussuceptive angiogenesis represents a part of the tumor protective adaptive response and may be a major reason for tumor therapy resistance and tumor recurrence.

In addition to angiogenesis, increasing evidence suggests that de novo vasculogenesis originating from endothelial precursor cells recruited from bone marrow or adipose tissue is also instrumental in experimental mouse and human breast tumor vascularization. Attracted by chemokines such as stromal derived factor (SDF)- $1 \alpha$, chemokine (C-C motif) ligand (CCL)-2 and -5 , precursor cells enter the tumor mass and differentiate into vascular sprouts which are then incorporated or connected to the in-growing vessels from the pre-existing vasculature [69]. Interestingly, chemotherapeutic or anti-angiogenic treatment leads to an acute and rapid mobilization of endothelial precursor cells into the tumor mass [70, 71]. Thus, in addition to the switch to intussuception, the recruitment of endothelial precursor cells might support the protective tumor response. In this respect, the dietary uptake of linoleic acid may represent an alternative route to inhibit the adaptive response. It has been shown that linoleic acid not only inhibits angiogenesis but also prevents the differentiation of adipose tissue-derived mesenchymal stem cells into the endothelial pathway [72]. 


\section{Synopsis}

From the knowledge gained to date it has become clear that the presence of a precisely-developed vasculature is imperative for the proper course of the mammary gland cycle. In contrast to most other organs of the body, where induction of angiogenesis occurs only in response to injury and originates from the stroma, the mammary parenchyma constantly regulates its own vasculature according to the changing functional demands. The fact that the mammary epithelium is able to regulate its own angiogenesis might be a main reason why mammary cancer cells are able to induce the angiogenic switch for their vascularization at a very early state during carcinogenesis [73]. Interestingly, among the different subtypes of breast cancer, the triple negative breast cancers seem to be especially potent in the induction of angiogenesis [66]. These triple negative breast tumor cells share many characteristics with the basal epithelial cells, where it is thought, that this progenitor cell population is the origin of cancer. Thus, it is conceivable that this cell population is also responsible for the initiation of angiogenesis during normal development. As potent as the mammary epithelium is in the induction of angiogenesis, it is equally potent in the induction of ordered vascular regression during involution. Although of potential therapeutic importance, the regulation of vascular retraction has so far received little attention. The observed decline in VEGF expression during lactation and involution may be instrumental in the attenuation of endothelial cell growth but is unlikely to be the only factor responsible for the massive reduction of the capillary network. Moreover, the apparently-contradictory role of cathepsin D regulating epithelial and endothelial regression, while also promoting metastatic tumor growth is poorly understood. Thus, deciphering the mechanisms involved in vascular retraction remains a challenging task for the future.

Angiogenesis during normal and malignant mammary epithelial development is induced by the epithelial secretion of pro-angiogenic factors. This stimulates vascularization which in turn supports epithelial proliferation and differentiation. It has to be kept in mind, however, that the same factors are also able to directly stimulate the epithelium itself. This is evident for the hormones estrogen, progesterone and prolactin, but it has also been shown that mammary epithelial cells possess VEGF receptors and that VEGF can induce epithelial cell proliferation in an autocrine manner [74, 75]. Moreover, the observed phenotypic consequences of VEGF inhibition in the mammary epithelium could also, at least partly, be brought about by the inhibited autocrine stimulation leading to the inhibition of epithelial proliferation and differentiation. Thus, by applying an anti-angiogenic therapy in breast cancer treatment, one may directly interfere with not only the malignant but also the normal epithelial cell properties.
It is thought that the main purpose of angiogenesis is to ensure a sufficient supply of oxygen and nutrients. However, the alteration of endothelial cell properties, as effected by the VEGF knock-out [22], was sufficient to impair epithelial polarization and secretory differentiation. This suggests that, in addition to allow nutrient supply, endothelial cells may also directly be involved in the regulation of the epithelium. This effect might be brought about by inductive paracrine stimulation or by direct epithelial-endothelial interactions. Indeed, Shekar et al. demonstrated in 2000 that the interaction with endothelial cells is a prerequisite for branching morphogenesis of MCF10 human mammary epithelial cells and that, in turn, the interaction supports endothelial growth and differentiation [76]. Since then, however, no additional information about the underlying inductive principle has become available. The mammary epithelium is surrounded by a sheet of myoepithelial cells and a basement membrane which separates the epithelium from the stromal compartment and a direct interaction of epithelial and endothelial cells seems unlikely. If an endothelial-epithelial crosstalk exists it is rather transmitted via the myoepithelium. There are, however, developmental stages, such as the terminal endbud during puberty or the lactating epithelium, where the myoepithelial cell layer is discontinuous and a direct interaction of epithelial cells with blood capillaries is conceivable. Our observation that epithelial expression of EphB4 or ephrin-B2 affects the development of the vasculature during lactation supports the notion that direct epithelial-endothelial interactions may be instrumental in the establishment of a functional tissue architecture. If the mutual interaction of epithelial and endothelial cells is indeed a prerequisite for the function of both partners it may also be instrumental for the support of tumor growth. This, however, would open a whole range of new therapeutic options. The blocking of these vital interactions would not only reduce the viability of both partners but due to the lack of intercellular communication might also prevent the adaptive response.

\section{Concluding Remark}

It is generally accepted that the microenvironment plays a crucial role for the proper development and functioning of the mammary gland. Whereas the crosstalk between the parenchyma, mesenchyme and adipose tissue is under extensive investigation, the importance of the vasculature, other than providing nutrients, has so far gained little attention. The vasculature, however, is likely to be of equal importance for the homeostasis of the mammary epithelium as the other stromal components. Thus, elucidation of the endothelialepithelial crosstalk and deciphering the inductive mechanisms 
will not only broaden our understanding of mammary gland development and physiology but also may offer new aspects for targeted anti-breast cancer therapies.

Acknowledgements The authors wish to thank Robert Strange for helpful discussions and critical reading of the manuscript.

Conflict of interest The authors have no conflict of interest.

\section{References}

1. Carmeliet P. Angiogenesis in health and disease. Nat Med. 2003;9:653-60.

2. Adams RH, Alitalo K. Molecular regulation of angiogenesis and lymphangiogenesis. Nat Rev Mol Cell Biol. 2007;8:464-78.

3. Djonov V, Schmid M, Tschanz SA, Burri PH. Intussusceptive angiogenesis: its role in embryonic vascular network formation. Circ Res. 2000;86:286-92.

4. Makanya AN, Hlushchuk R, Djonov VG. Intussusceptive angiogenesis and its role in vascular morphogenesis, patterning and remodelling. Angiogenesis 2007;12:113-23.

5. Kässmeier S, Plendl J, Custodis P, Bahramsoltani M. New insights in vascular development: vasculogenesis and endothelial progenitor cells. Anat Histol Embryol. 2009;38:1-11.

6. Rabbany SY, Heissig B, Hattori K, Rafii S. Molecular pathways regulating mobilization of marrow-derived stem cells for tissue vascularization. Trends Mol Med. 2003;9:109-17.

7. Papayannopoulou T. Current mechanitstic scenarios in hematopoietic stem/progenitor cell mobilization. Blood 2004;103:1580-5.

8. Masuda H, Kalka C, Takahashi M, Yoshida M, Wada M, Kobori $\mathrm{R}$, et al. Estrogen-mediated endothelial progenitor cell biology and kinetics for physiological postnatal vasculogenesis. Circ Res. 2007;101:598-606.

9. Djonov V, Andres A-C, Ziemiecki A. Vascular remodelling during the normal and malignant life cycle of the mammary gland. Microsc Res Tech. 2001;52:182-9.

10. In G, Garcia M, Ning H, Banie L, Guo YL, Lue TF, et al. Defining stem and progenitor cells within adipose tissue. Stem Cells Dev. 2008;17(6):1053-63.

11. Hamou C, Callaghan MJ, Thangarajah H, Chang E, Chang EI, Grogan RH, et al. Mesenchymal stem cells can participate in ischemic neovascularization. Plast Reconstr Surg. 2009;123 (2Suppl):45S-55S.

12. Matsumoto $M$, Nishinakagawa $H$, Kurohmaru M, Hayashi $Y$, Otsuka J. Pregnancy and lactation affect the microvasculature of the mammary gland in mice. J Vet Med Sci. 1992;54(5):93743.

13. Abdul-Awal M, Matsumoto M, Toyoshima $Y$, Nishinakagawa $H$. Ultrastructural and morphometrical studies on the endothelial cells of arteries supplying the abdomino-inguinal mammary gland of rats during the reproductive cycle. J Vet Med Sci. 1996;58(1):29-34.

14. Walker NI, Bennett RT, Kerr JF. Cell death by apoptosis during involution of the lactating breast in mice and rats. Am J Anat. 1989;185:19-32.

15. Sevennersten-Sjaunja K, Olsson K. Endicrinology of milk production. Domest Anim Endocrinol. 2005;29(2):241-58.

16. Naccarato AG, Viacava P, Bocci G, Fanelli G, Aretini P, Lonobile A, et al. Definition of the microvascular pattern of the normal human adult mammary gland. J Anat. 2003;203(6):599-603.

17. Breen EC. VEGF in biological control. J Cell Biochem. 2007;102:1358-67.

18. Qiu Y, Bevan H, Weeraperuma S, Wratting D, Murphy D, Neal $\mathrm{CR}$, et al. Mammary alveolar development during lactation is inhibited by the endogenous antiangiogenic growth factor isoform VEGF $_{165}$ b. FASEB J. 2008;22:1104-12.

19. Pepper MS, Baetens D, Mandriota SJ, Di Sanza C, Oikemus S, Lane TF, et al. Regulation of VEGF and VEGF receptor expression in the rodent mammary gland during pregnancy, lactation and involution. Dev Dyn. 2000;218:507-24.

20. Hovey RC, Goldhar AS, Baffi J, Vonderhaar BK. Transcriptional regulation of vascular endothelial growth factor expression in epithelial and stromal cells during mouse mammary gland development. Mol Endocrinol. 2001;15(5):819-31.

21. Islam MS, Matsumoto M, Ishida R, Oka T, Kanouchi H. Change in VEGF expression in mouse mammary gland during reproductive cycle. J Vet Med Sci. 2010; e-pub ahead of print.

22. Rossiter H, Barresi C, Ghannadan M, Gruber F, Mildner M, Födinger $\mathrm{D}$, et al. Inactivation of VEGF in mammary gland epithelium severely compromises mammary gland development and function. FASEB J. 2007;21:3994-4004.

23. Semenza GL. HIF-1 and human disease: one highly involved factor. Genes Dev. 2000;14:1983-91.

24. Seagroves TN, Hadsell D, McManaman J, Palmer C, Liao D, McNulty W, et al. Hifl $\alpha$ is a critical regulator of secretory differentiation and activation, but not vascular expansion, in the mouse mammary gland. Development 2003;130:1713-24.

25. Brisken C, Rajaram RD. Alveolar and lactogenic differentiation. J Mammary Gland Biol Neoplasia. 2006;11(3-4):239-48.

26. Mallepel S, Krust A, Chambon P, Brisken C. Paracrine signalling through the epithelial estrogen receptor alpha is required for proliferation and morphogenesis in the mammary gland. Proc Natl Acad Sci USA. 2006;103(7):2196-201.

27. Dabrosin C. Sex steroid regulation of angiogenesis in breast tissue. Angiogenesis 2005;8:127-36.

28. Cid MC, Schnaper W, Kleinman HK. Estrogens and the vascular endothelium. Ann NY Acad Sci. 2002;966:143-57.

29. Hyder SM. Sex steroid regulation of vascular endothelial growth factor in breast cancer. Endocr Relat Cancer. 2006;13:667-87.

30. Bogin L, Degani H. Hormonal regulation of VEGF in orthotopic MCF-7 human breast cancer. Cancer Res. 2002;62:1948-51.

31. Dabrosin C. Variability of vascular endothelial growth factor in normal human breast tissue in vivo during the estrous cycle. J Clin Endocrinol Metab. 2003;88:2695-8.

32. $\mathrm{Wu} \mathrm{J}$, Richer J, Horwitz KB, Hyder S. Progestin-dependent induction of vascular endothelial growth factor in human braest cancer cells: preferential regulation by progesterone receptor $\mathrm{B}$. Cancer Res. 2004;64:2238-44.

33. Kazi AA, Jones JM, Koos RD. Chromatin immunoprecipitation analysis of gene expression in the rat uterus in vivo: estrogeninduced recruitment of both estrogen receptor alpha and hypoxia inducible factor 1 to the vascular endothelial growth factor promoter. Mol Endocrinol. 2005;19:2006-19.

34. Molitoris KH, Kazi AA, Koos RD. Inhibition of oxygen-induced hypoxia-inducible factor-1alpha degradation unmasks estradiol induction of vascular endothelial growth factor expression in ECC-1 cancer cells. Endocrinology 2009;150:5405-14.

35. Ogba N, Doughman YQ, Chaplin LJ, Hu Y, Gargesha M, Watanabe $\mathrm{M}$, et al. HEXIM1 modulates vascular endothelial growth factor expression and function in breast epithelial cells and mammary gland. Oncogene 2010;29:3939-49.

36. Schulze K, McGowan KA, Hubchak S. Expression of an estrogen receptor by human coronary artery and umbilical vein endothelial cells. Circulation 1996;94:1402-7.

37. Schwertfeger KL, Rosen JM, Cohen DA. Mammary gland macrophages: pleiotropic functions in mammary development. J Mammary Gland Biol Neoplasia. 2006;11:229-38.

38. Neville MC, MCFadden TB, Forsyth I. Hormonal regulation of mammary differentiation and milk secretion. J Mammary Gland Biol Neoplasia. 2002;7:49-66. 
39. Corbacho AM, Martinez De la Escalera G, Clapp C. Roles of prolactin and related members of the prolactin/growth hormone/ placental lactogen family in angiogenesis. J Endocrinol. 2002;173:219-38.

40. Clapp C, Thebault S, Martinez De La Escalera G. Role of prolactin in the regulation of vascular function in mammary gland. J Mammary Gland Biol Neoplasia. 2008;13:55-67.

41. Merkle CJ, Schuler LA, Schaeffer RC, Gribbon JM, Montgomery DW. Structural and functional effects of high prolactin levels on injured endothelial cells: evidence for an endothelial prolactin receptor. Endocr 2000;13:37-46.

42. Ueda E, Ozerdem U, Chen YH, Yao M, Huang KT, Sun H, et al. A molecular mimic demonstrates that phosphorylated human prolactin is a potent anti-angiogenic hormone. Endocr Relat Cancer. 2006;13:95-111.

43. Ricken AM, Traenkner A, Merkwitz C, Hummitzsch K, Grosche $\mathrm{J}$, Spanel-Borowski K. The short prolactin receptor predominates in endothelial cells of micro- and macrovascular origin. J Vasc Res. 2007;44:19-30.

44. Goldhar AS, Vanderhaar BK, Trott JF, Hovey RC. Prolactininduced expression of vascular endothelial growth factor via Egr1. Mol Cell Endocrinol. 2005;232:9-19.

45. Clapp C, Aranda J, Gonzalez C, Jeziorski MC, Martinez De La Escalera G. Vasoinhibins: endogenous regulators of angiogenesis and vascular function. Trends Endocrinol Metab. 2006;17:301-7.

46. Baldocchi RA, Tan L, Nicoll CS. Processing of rat prolactin by rat tissue explants and serum in vivo. Endocrinology 1992;130:16539.

47. Macotela Y, Aguilar MB, Guzman-Morales J, Rivera JC, Zemeno C, Lopez-Barrera F, et al. Matrix metalloproteases from chondrocytes generate an anti-angiogenic $16 \mathrm{kDa}$ prolactin. J Cell Sci. 2006;119:1790-800.

48. Ge G, Greenspan DS. Developmental roles of the BMP1/TLD metalloproteinases. Birth Defects Res Embryo Today. 2006;78:47-68.

49. Tang J, Wong RN. Evolution in the structure and function of aspartic proteases. J Cell Biochem. 1987;33:53-63.

50. Lkhider M, Castino R, Bouguyon E, Isidoro C, Olliver-Bousquet M. Cathepsin D released by lactating mammary epithelial cells is involved in prolactin cleavage under physiological conditions. J Cell Sci. 2004;117:5155-64.

51. Castino R, Delpal S, Bouguyon R, Isidoro C, Olliver-Bousquet M. Prolactin promotes the secretion of active cathepsin D at the basal side of rat mammary acini. Endocrinology 2008;149:4095-105.

52. Zaragoza R, Torres L, Garcia C, Eroles P, Corrales F, Bosch A, et al. Nitration of cathepsin $\mathrm{D}$ enhances its proteolytic activity during mammary gland remodelling after lactation. Biochem J. 2009;419:279-88.

53. Castino R, Bellio N, Nicotra G, Follo C, Trinchera NF, Isidoro C. Cathepsin d-Bax death pathway in oxidative stressed neuroblastoma cells. Free Radical Biol Med. 2007;42:1305-16.

54. Zhang J, Hughes S. Role of the ephrin and Eph receptor tyrosine kinase families in angiogenesis and development of the cardiovascular system. J Pathol. 2006;208:453-61.

55. Erber R, Eichelsbacher U, Powajbo V, Korn T, Djonov V, Lin J, et al. EphB4 controls blood vascular morphogenesis during postnatal angiogenesis. EMBO J. 2006;25:628-41.

56. Sawamiphak S, Seidel S, Essmann CL, Wilkinson GA, Pitulescu ME, Acker T, et al. Ephrin-B2 regulates VEGFR2 function in developmental angiogenesis. Nature 2010;465:487-91.

57. Wang Y, Nakamura M, Pitulescu ME, Schmidt TS, Bochenek ML, Sakakibara A, et al. Ephrin-B2 controls VEGF-induced angiogenesis and lymphangiogenesis. Nature 2010;465:483-6.

58. Nikolova Z, Djonov V, Zürcher G, Andres A-C, Ziemiecki A. Cell-type specific and estrogen dependent expression of the receptor tyrosine kinase EphB4 and its ligand ephrin-B2 during mammary gland morphogenesis. J Cell Sci. 1998;111:2741-51.

59. Munarini N, Jaeger R, Abderhalden S, Zürcher G, Rohrbach V, Lörcher $\mathrm{S}$, et al. Altered mammary epithelial development, pattern formation and involution in transgenic mice expressing the EphB4 receptor tyrosine kinase. J Cell Sci. 2002;115:25-37.

60. Haldimann M, Custer D, Stirnimann C, Munarini N, Weiler S, Zürcher G, et al. Deregulated ephrin-B2 expression interferes with the development of both the glandular epithelium and vasculature and promotes metastasis formation. Int J Oncol. 2009;35:525-36.

61. Andres A-C, Ziemiecki A. Eph and ephrin signalling in mammary gland morphogenesis and cancer. J Mammary Gland Biol Neoplasia. 2003;8:475-85.

62. Schneider BP, Miller KD. Angiogenesis of breast cancer. J Clin Oncol. 2005;23:1782-90.

63. Chen A, Cuevas I, Kenny PA, Miyake H, Mace K, Ghajar C, et al. Endothelial cell migration and vascular growth factor expression are the result of loss of breast tissue polarity. Cancer Res. 2009;69:6721-9.

64. Bossung V, Harbeck N. Angiogenesis inhibitiors in the management of breast cancer. Curr Opin Obstet Gynecol. 2010;22:79-86.

65. Gordon MS, Mendelson DS, Kato G. Tumor angiogenesis and novel antiangiogenic strategies. Int J Cancer. 2010;126:1777-87.

66. Greenberg S, Rugo HS. Triple-negative breast cancer: role of antiangiogenic agents. Cancer J. 2010;16:33-8.

67. Benjamin LE, Golijanin D, Itin A, Pode D, Keshet E. Selective ablation of immature blood vessels in established human tumors follows vascular endothelial growth factor withdrawal. J Clin Invest. 1999;103:159-65.

68. Hlushchuk R, Riestener O, Baum O, Wood J, Gruber G, Pruschy $\mathrm{M}$, et al. Tumor recovery by angiogenic switch from sprouting to intussusceptive angiogenesis after treatment with PTK787/ ZK222584 or ionizing irradiation. Am J Pathol. 2008;173:117385.

69. Le Bourhis X, Romon R, Hondermarck H. Role of endothelial progenitor cells in breast cancer angiogenesis: from fundamental research to clinical ramification. Breast Cancer Res Treat. 2010;120:17-24.

70. Shaked Y, Ciarrocchi A, Franco M, Lee CR, Man S, Cheung AM, et al. Therapy-induced acute recruitment of circulating endothelial progenitor cells to tumors. Science 2006;313:1785-7.

71. Shaked Y, Henke E, Roodhart JM, Manusco P, Langenberg MH, Colleoni M, et al. Rapid chemotherapy-induced acute endothelial progenitor cell mobilization: implications for antiangiogenic drugs as chemosensitizing agents. Cancer Cell. 2008;14:263-73.

72. Ip MM, Masso-Welch PA, Ip C. Prevetion of mammary cancer with conjugated linoleic acid: role of the stroma and the epithelium. J Mammary Gland Biol Neoplasia. 2003;8:103-17.

73. Sturm JM. Angiogenic responses elicited from chorioallantoic membrane vessels by neoplastic preneoplastic and normal mammary tissues from GR mice. Am J Pathol. 1983;111:282-7.

74. Masood R, Cai J, Zheng T, Smith DL, Hinton DR, Gill PS. Vascular endothelial growth factor (VEGF) is an autocrine growth factor for VEGF positive human tumors. Blood 2001;98:190413.

75. Schoeffner DJ, Matheny SL, Akahane T, Factor V, Berry A, Merlino G, et al. VEGF contributes to mammary tumor growth in transgenic mice through paracrine and autocrine mechanisms. Lab Invest. 2005;85:608-23.

76. Shekar MP, Werdell J, Tait L. Interaction with endothelial cells is a prerequisite for branching ductal-alveolar morphogenesis and hyperplasia of preneoplastic human breast epithalial cells: regulation by estrogens. Cancer Res. 2000;60:439-49.

77. Djonov V, Baum O, Burri PH. Vascular remodelling by intussusceptive angiogenesis. Cell Tissue Res. 2003;314:107-17. 